\title{
輝尽性蛍光体の瞬時発光を利用したCRシステムの プリサンプリングMTFの予测と問題点
}

\author{
小野喜太平・稲津 博・原尾基継・糸永治夫・宮本秀幸 \\ 日本文理大学NBUメディカルカレッジ放射線学科
}

2001 年 1 論文受理

Code No. 254

緒 言

ディジタル方式医用画像の利益はX線CTによって明 らかにされ，その後のディジタル画像機器の積極的な 開発につながった。なかでも, 従来の増感紙ーフィル ム系と同じ特性の画像を作成することを目標に開発さ れたコンピューテッドラジオグラフィ $(\mathrm{CR})$ は医用画
像に大きなインパクトを与えた。とくに，カセッテタ イプのCRは，使い慣れている増感紙一フィルム系と画 像作成扔よび診断においてほとんど同じ取り扱いがで き，常にほほ適切な写真濃度の画像が得られるという 利点のために, 多くの病院で広く導入され，著しい普 及を示した。

\section{Estimation of Presampling MTF in CR Systems by Using Direct Fluores- cence and Its Problems}

\section{KITAHEI ONO, HIROSHI INATSU, MOTOTSUGU HARAO, HARUO ITONAGA, and HIDEYUKI MIYAMOTO}

Department of Radiological Technology, NBU Medical College, Nippon Bunri University

Received July 19, 2000; Revision accepted Jan. 29, 2001; Code No. 254

\section{Summary}

We proposed a method for practical estimation of the presampling modulation transfer function(MTF) of a computed radiography $(\mathrm{CR})$ system by using the MTFs of an imaging plate and the sampling aperture. The MTFs of three imaging plates (GP-25, ST-VN, and RP-1S) with different photostimulable phosphors were measured by using direct fluorescence (the light emitted instantaneously by x-ray exposure), and the presampling MTFs were estimated from these imaging plate MTFs and the sampling aperture MTF. Our results indicated that for imaging plate RP-1S the measured presampling MTF was significantly superior to the estimated presampling MTF at any spatial frequency. This was because the estimated presampling MTF was degraded by the diffusion of direct fluorescence in the protective layer of the imaging plate's surface. Therefore, when the presampling MTF of the imaging plate with a thick protective layer is estimated, correction for the thickness of the protective layer should be carried out. However, the estimated presampling MTF of imaging plates with a thin protective layer were almost the same as the measured presampling MTF, except in the high spatial frequency range. Therefore, we consider this estimation method to be useful and practical, because the spatial resolution property of a CR system can be obtained simply from the imaging plate MTF measured with direct fluorescence.

Key words: Imaging plate modulation transfer function $(M T F)$, Imaging plate intrinsic property, Imaging plate intrinsic resolution 


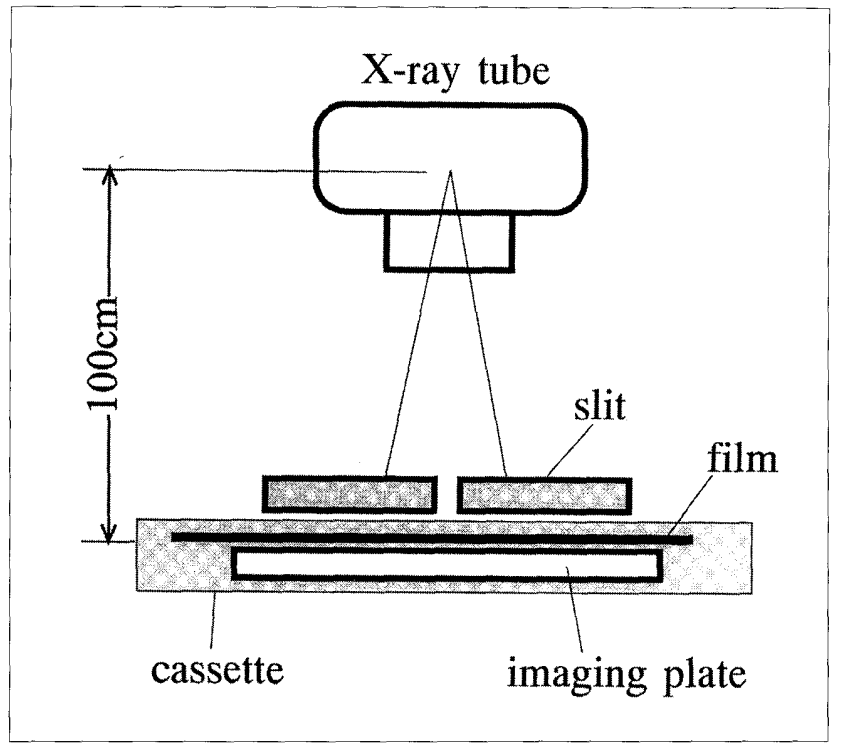

Fig. 1 Schematic diagram of experimental arrangement.

このような背景から，近年，いくつかのカセッテタ イプCR装置が開発された。これに伴って，X線画像情 報検出器として異なる輝尽性蛍光体を用いたイメージ ングプレート(IP) が発表され，堌感紙と同様にCRに 括いても性能の異なるIPが開発されつつある。したが って，使用者はこれらの多くのIPのなかから目的にあ ったIPを選択して使用する時代に向かうと考えられ る.

増感紙一フィム系の画質は打もに増感紙に支配さ れる。したがって，増感紙ーフィルム系では增感紙の 性能を知ることによって系の鮮鋭度に関する特性を知 ることができる。これに対して，CRはIPに固有の性 能のほかに励起レーザ光の線束径，標本間隔抢よび標 本開口寸法など，多くの要素の影響を受ける1”。 ため，CRの鮮鋭度や雑音などの特性は，実際に装置 を導入するまで測定することができない。しかしその 一方，前述のようにIPの種類が増加すると使用者が前 もってIPの性能を簡単に測定し，その結果と診断目的 に基づいてIPを選択する必要がある。

そこで，比較的簡単にCR系の鮮鋭度を知る方法と して，瞬時発光を利用して測定したIPのMTFからプリ サンプリングMTFを予測することを試みた．IPから得 られる初期データはアナログ信号である。これを $\mathrm{A} / \mathrm{D}$ 変換器でディジタル信号に変換するのであるから，鮮 鋭度はアナログの状態で測定できる。しかも，アナロ グ段階での性能測定では，従来の手法が使用できるは ずである2,3).

本論文の目的はIPの瞬時発光を利用して, 装置購入 前にプリサンプリングMTFを予測し，その問題点を洗 い出すこと，および予測したプリサンプリングMTFと
実際に測定したプリサンプリングMTFを比較すること である。

\section{1. 実験方法}

実験に使用したIPはGP-25[BaFBr: Eu，コダック株 式会社製 $], S T-V_{N}[B a F(B r . I): E u ，$ 富士写真フィルム 株式会社製]扔よびRP-1S [BaFI: Eu，コニカ株式会社 製了である。また，瞬時発光を記録する道具として CRT用片面乳棛フィルム (SR-IC，コニカ株式会社製) を使用した。

MTFはスリット法で測定した。まず，線像濃度分布 は，幅10 $\mu \mathrm{m}$ のスリットをIPを納めたカセッテの前面

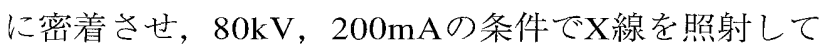

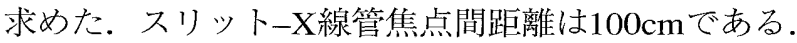
また，カセッテのX線管球側にフィルムを置き，その 後ろにIPを配置した。実験配置図をFig. 1に示す。

露光は基準露光抢よび基準露光の 5 倍の倍数露光 を用い，倍数露光法㧍よび指数関数近似でトランケ ーションエラーを補正した。線像濃度分布はマイク ロデンシトメータの開口 $10 \times 800 \mu \mathrm{m}^{2}$ でフィルムを走 查して求めた．この後，別に測定した瞬時発光によ る特性曲線を用いて有効露光に変換し, 線像强度分 布を得た。

特性曲線はインバー夕式X線装置(KXO-30F: 東芝メ ディカル株式会社製)を用い，銅1.0mm厚のフィルタ を付加して $80 \mathrm{kV} ， 100 \mathrm{~mA} ， 0.1 \mathrm{sec} の$ 条件でX線を照射 して求めた。また，比較のためにRP-1Sのプリサンプ リングMTFを測定した。このとき，X線照射条件は瞬 時発光のときと同じである.

\section{2. 結果および考察}

Fig. 2 に 3 種類のIPの瞬時発光による特性曲線を示 す. RP-1Sの相対的な発光強度を100とすると，ST-V は76, GP-25は57であった。

Fig. 3 に瞬時発光で求めた 3 種類のIPのMTF $\left[M T F_{M}\right.$ (u) ]を示す１.5cycles/mmで比較したときのMTF值は RP-1S とST-VNが0.45で同じであり, 最も鮮鋭度が劣 るのはGP-25の0.37である。

簡単のため一次元で考える。一般に，ディジタルシ ステムに扮ける鮮鋭度はプリサンプリング $\mathrm{MTF}$ $\left[M T F_{P R E}(u)\right] て ゙$ 評価される。IPを非常に細いレーザ光 で走查して得られるIP固有のアナログMTFを $M T F_{A}(u)$ と抢けばMTFPRE $(u)$ は

$$
\operatorname{MTF}_{P R E}(u)=M T F_{A}(u) \cdot \operatorname{sinc}(\pi d u)
$$

である4).ここで, $\operatorname{sinc}(\pi d u)$ は標本開口寸法が $\mathrm{d}$ と きの空間周波数特性である。 


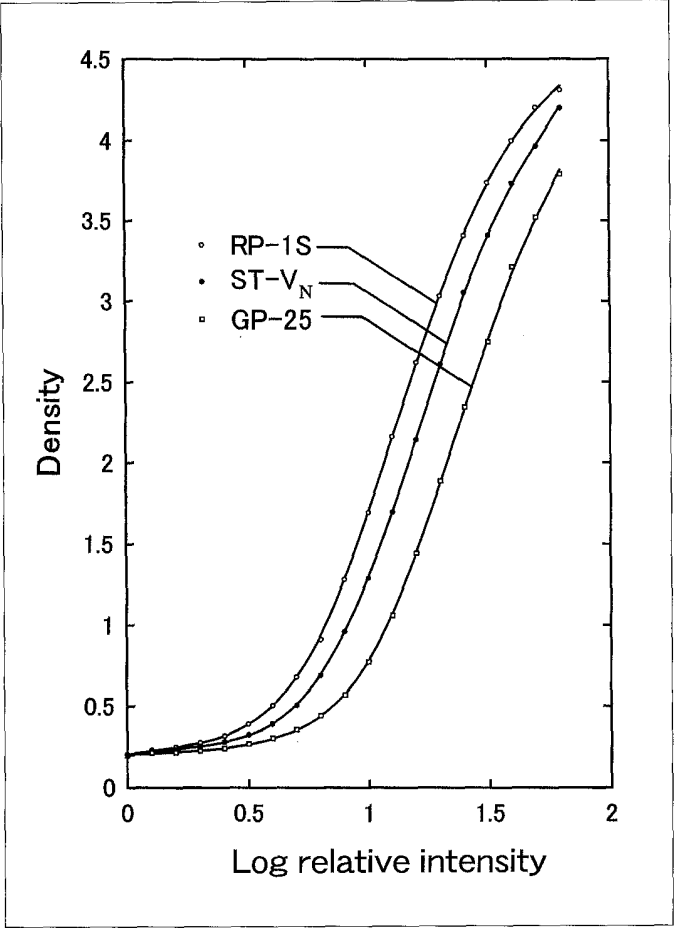

Fig. 2 Characteristic curves of three different imaging plates $\left(R P-1 S, S T-V_{N}\right.$, and GP. 25) with single coated films (SR-IC), obtained by using direct fluorescence.

いま，この実験で求めた $M T F_{M}(u)$ が $M T F_{A}(u)$ であれ ばIPの基本性能を表す。しかし，MTFM $(u)$ はIPをレー ザ光で走査するときのレーザ光の拡散による影響が含 まれていないので, $M T F_{A}(u)$ と等しくない.

いま, $M T F_{A}(u)$ を次のように二段階に分けて考え る、第一段階ではIPに入射したX線は蛍光体を励起さ せ，励起された電子の大部分は捕獲中心に捕獲される が，残りの電子は増感紙と同様に䋏光を発して基底状 態に戻る。この蛍光をここでは瞬時発光と呼び, 今回 はこの現象を利用して $M T F_{M}(u)$ を測定した。したがっ て，この笑験で求めた $M T F_{M}(u)$ は増感紙のそれとまっ たく同じである。

第二段階では, IP蛍光体に励起光を照射し, 輝尽発 光を行わせる. CRにおけるIPのMTF $F_{P R E}(u)$ は，この段 階の発光を利用して測定される。たたし，エリアシン グエラーを除くため，標本間隔の影響を除いている。 したがって，MTFPRE $(u)$ は第一および第二段階の両方 の過程を含んたMTFである。そこで， $M T F_{M}(u)$ と $M T F_{A}(u)$ 相異が小さいのであれば $M T F_{M}(u)$ から $M T F_{P R E}(u)$ を予測することができるはずである.

今回測定した $M T F_{M}(u)$ と $M T F_{A}(u)$ の間にはいくつか の相異点がある。 $M_{T} F_{M}(u)$ は第一段階だけの特性であ る. $\operatorname{MTF}_{M}(u)$ は, $\operatorname{MTF}_{A}(u)$ と比較して瞬時発光の拡散 を含むことと，散乱X線によって発光中心から離れた

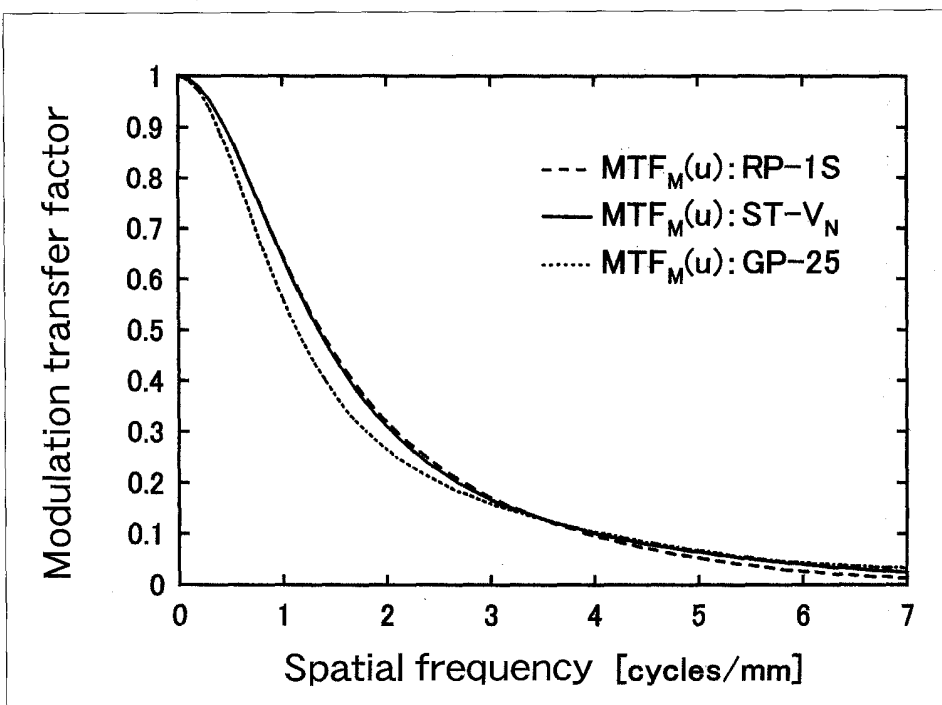

Fig. 3 MTFs of three different imaging plates (RP-1S, ST- $V_{N}$, and GP-25) obtained by using direct fluorescence $\left[M T F_{M}(u)\right]$.

場所に捕獲された電子によるMTFの劣化，および斺起 光の拡散の影響を含んでいないなど, $M T F_{A}(u)$ とは微 妙に異なっている。そこで，この実験で求めた $M T F_{M}$ (u) を式(2)で処理して求めた予測プリサンプリング $\operatorname{MTF}\left[M T F_{S}(u)\right]$ と, CR装置(REGUS-150)を用いて求 めた $\operatorname{MTF}_{P R E}(u)$ を比較した。

$$
\operatorname{MTF}_{S}(u)=\operatorname{MTF} F_{M}(u) \cdot \operatorname{sinc}(\pi d u)
$$

このとき, $\operatorname{sinc}(\pi d u)$ はdを $175 \mu \mathrm{m}$ (メーカ公称值) とし て計算した。

結果をFig. $4 \mathrm{a}$ に示す. $M T F_{M}(u)$ に含まれる瞬時発光 の拡散が無視できるのであれば， $M T F_{P R E}(u)$ は開口寸 法効果やレーザ光の拡散効果が付加されているために $M T F_{S}(u)$ より低い值となるはずである。しかし，Fig. $4 \mathrm{a}$ に示すようにRP-1SのIPにおけるMTFs $(u)$ と $M T F_{P R E}$ $(u)$ の関係は前述の傾向と一致しない。この原因とし てIPの保護膜による瞬時発光の拡散が影響していると 考えられる．RP-1Sの蛍光体は強い潮解性があるため に比較的厚い保護層を用いて防湿を行っているＩPの 保護層の厚さはレーザ光の拡散をまねき鮮鋭度を低下 させるが，RP-1Sでは散乱防止層を設けることで鮮鋭 度の低下を回避している。このため，保護層による $M T F_{P R E}(u)$ の低下はほとんどない5)。しかし，IPとフ イルムを組み合わせて瞬時発光を利用した今回の実験 では，保護膜はフィルムと蛍光体を密着不良状態にす るのでMTFM $(u)$ は低下する。このため, $M T F_{S}(u)$ の值 はMTF $F_{P R E}(u)$ よりすべての周波数で低い值となる.

保護膜による影響を確かめるために，保護膜を取り 

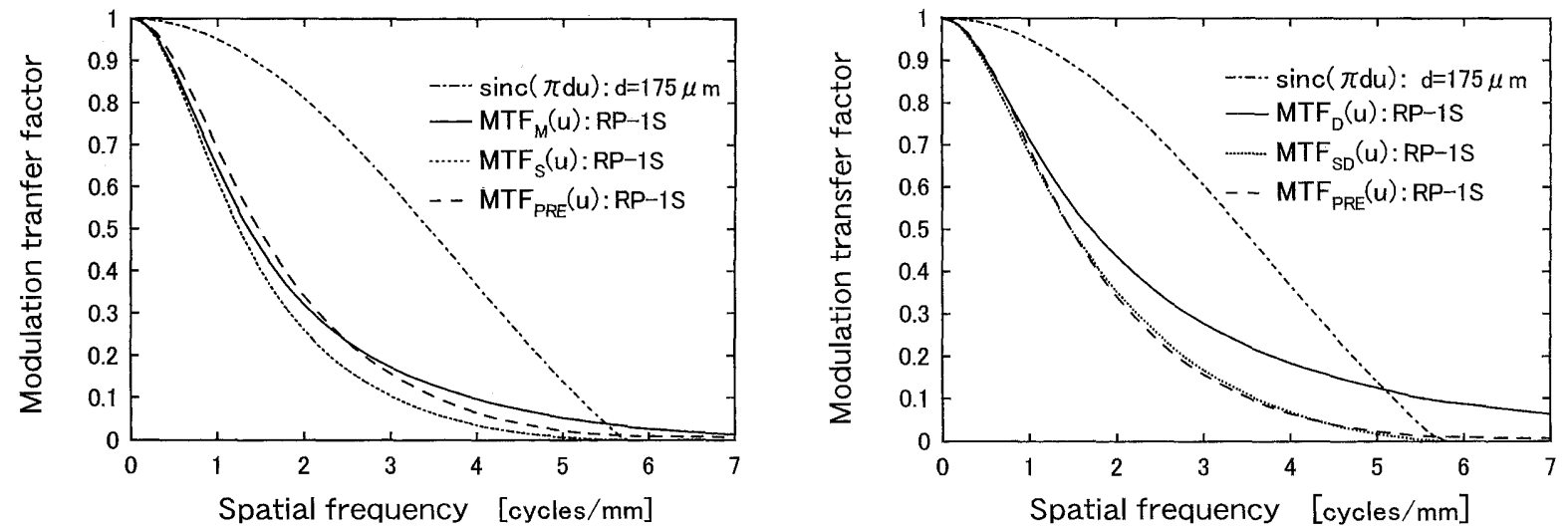

Fig. 4 Various MTFs for the RP-1S imaging plate.

a: With $68 \mu \mathrm{m}$ thick protective layer.

$\mathrm{b}$ : Without protective layer.

$\operatorname{MTF}_{M}(u)$ or $\operatorname{MTF}_{D}(u)$ : Imaging plate MTF obtained by direct fluorescence, MTFs $(u)$ or MTFSD $(u)$ : estimated presampling MTF, MTFPRE $(\mathrm{U})$ : actually measured presampling MTF, and sinc $(\pi \mathrm{du})$ : sampling aperture MTF.

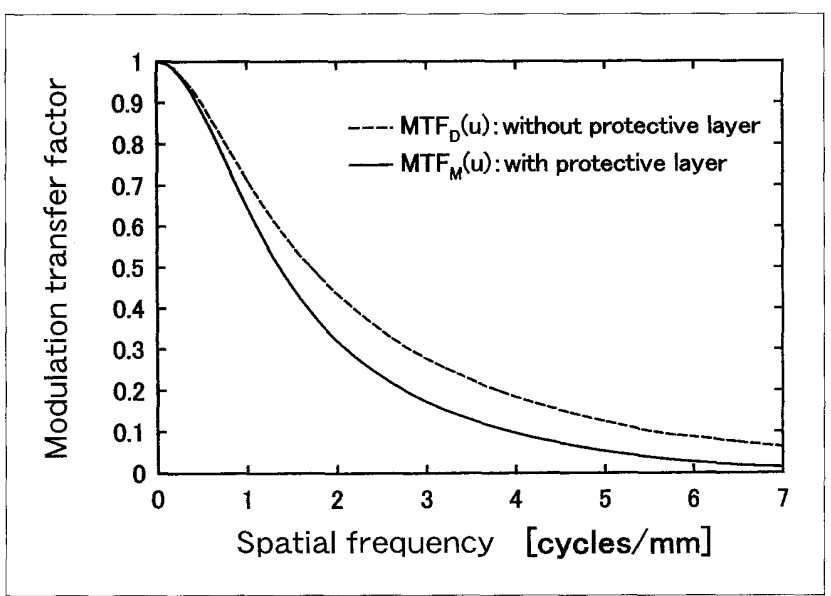

Fig. 5 Imaging plate MTFs with $68 \mu \mathrm{m}$ thick protective layer and without protective layer.

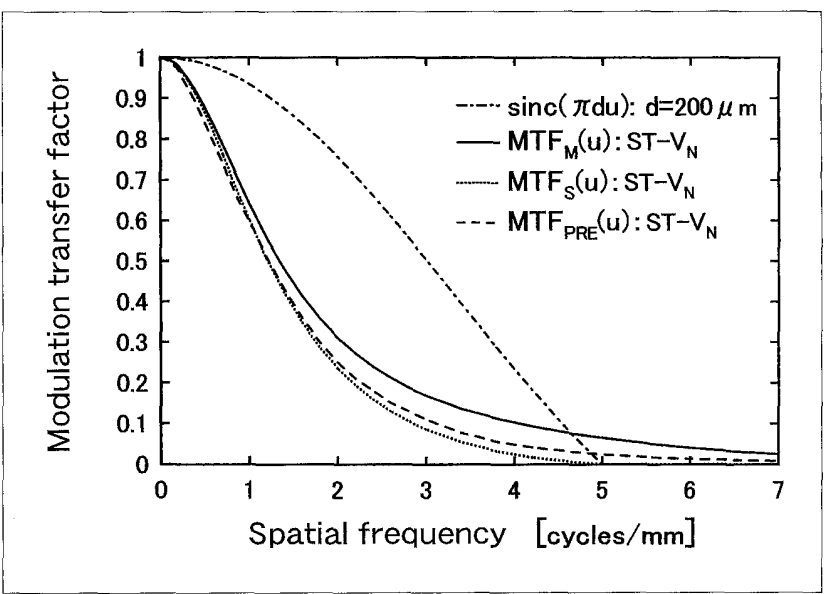

Fig. 6 Various MTFS for the ST- $\mathrm{V}_{\mathrm{N}}$ imaging plate.

$d$ を $200 \mu \mathrm{m}$ (メーカ公称値) として計算した. MTFPRE $(\boldsymbol{u})$ の值はST-VNとST-V (富士写真フィルム株式会社 製)でほとんど等しい6)。このため, 西原らが求めた ST-Vの值を参考にした7). Fig. 6のMTFPRE $(u)$ とMTFS (u)との関倸は, RP-1Sほどの差はなく, 両者はほほ 一致する。この原因はST-VN保護膜の厚さが $9 \mu \mathrm{m}^{6)}$ あり，RP-1Sよりかなり薄いためである。

この保護層による不鋭は増感紙一フィルム系の密着 不良による不鋭と同じであるから，増感紙一フィルム 系の密着不良によるMTFが使えるはずである。この密 着による不鋭の一次元MTF $\left[P_{X}(u)\right]$ は次のように示さ れる8).
Fig. 6にST-VNOsinc $(\pi d u), \operatorname{MTF}_{M}(u), M_{N} F_{S}(u)$ お よび $M T F_{P R E}(u)$ の関係を示す。このとき, $\operatorname{sinc}(\pi d u)$ は

$$
P_{X}(u)=2 \pi l u \cdot K_{1}(2 \pi l u)
$$




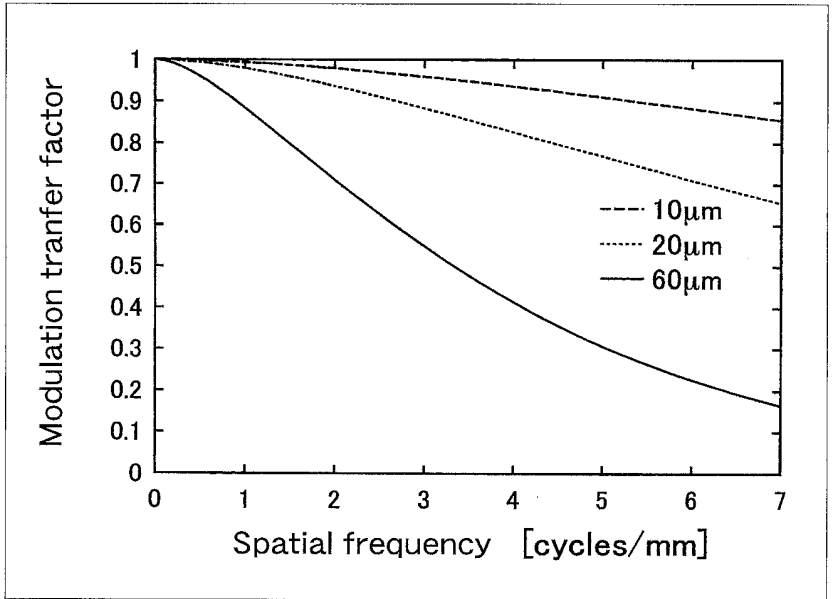

Fig. $7 \quad P x(u)$ : MTF degradation caused by diffusion in protective layers of 10,20 , and $60 \mu \mathrm{m}$ thick.

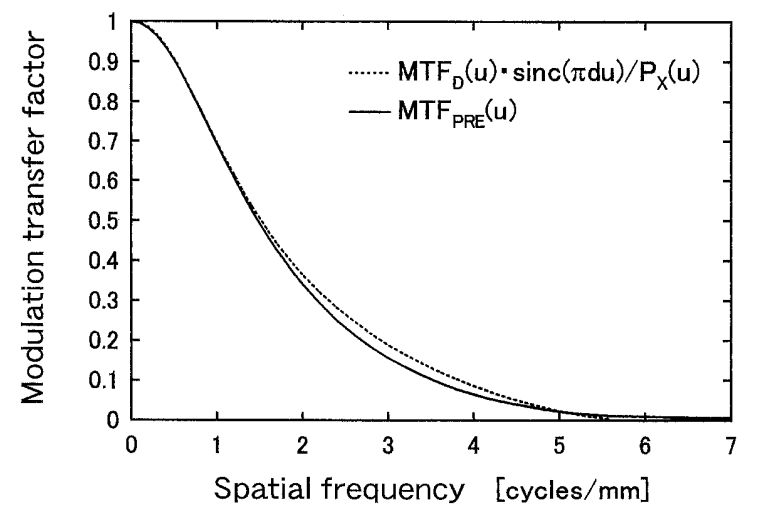

Fig. 8 Estimated presampling MTF obtained by correction in $P_{x}(u)$ with a $60 \mu \mathrm{m}$ thick protective layer [MTFD (u) $\cdot \operatorname{sinc}(\pi d u) / P \times(u)]$ and actually measured presampling MTF for the RP-1S imaging plate.

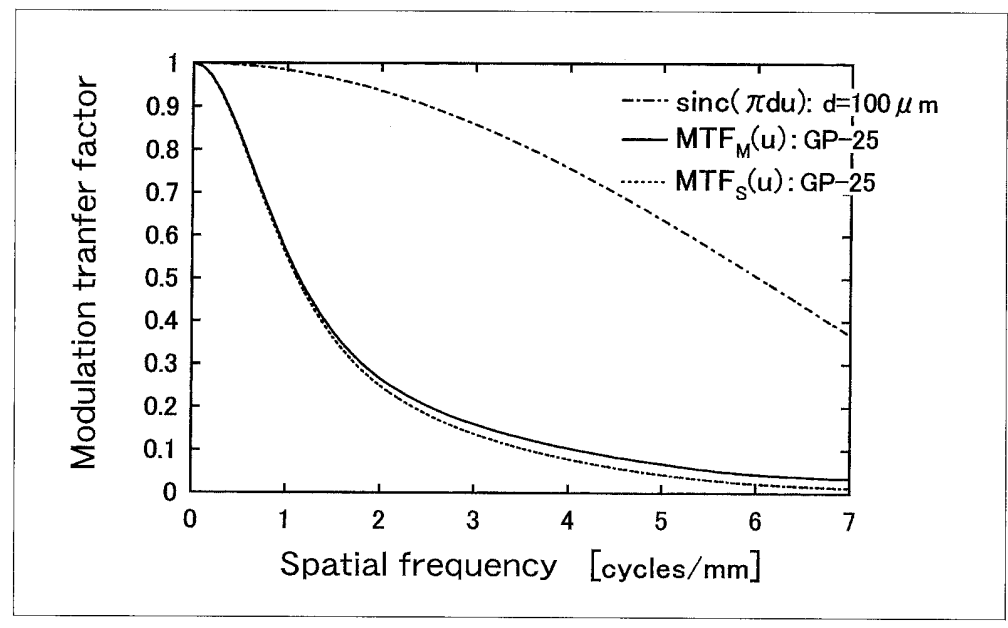

Fig. 9 Various MTFs for the GP-25 imaging plate.

\section{$K_{1} ：$ 変形ベッセル関数 \\ $l$ : 保護層の厚导 \\ $u$ : 空間周波数}

Fig. 7 に，保護膜の厚さが $10 ， 20,60 \mu \mathrm{m}$ のきの $P_{X}$ (u) を示す。保護層 $10 \mu \mathrm{m}$ では，空間周波数 3cycles/ $\mathrm{mm}$ でも劣化は約4\%(4.1\%)であり，ほとんど補正の 必要がないことが分かる。

Fig. 8に，保護膜の厚さが $60 \mu \mathrm{m} の$ ときの $P_{X}(u)$ を用 いて補正した予測プリサンプリングMTF $\left[M T F_{D}(u) \cdot\right.$ $\left.\operatorname{sinc}(\pi d u) / P_{X}(u)\right]$ と実測プリサンプリング $\mathrm{MTF}$ $\left[M T F_{P R E}(u)\right]$ を示す. Fig. 8は，中間周波数領域で補正
が十分でないが，低周波数領域では良好に補正されて いることを示している。

Fig. 8のようにRP-1Sでは，保護膜の厚さを考慮に入 れ検討する必要がある。しかし，保護層が $9 \mu \mathrm{m} の \mathrm{ST}$ $\mathrm{V}_{\mathrm{N}}$ は, $M T F_{P R E}(\boldsymbol{u})$ とMTFS $(\boldsymbol{u})$ の関係がほぼ一致する。 このため, ST-VNでは保護層を考慮に入れず瞬時発光 を利用してIPのMTFを测定し，プリサンプリング MTFを予測しても大きな誤差は発生しない。

Fig. 9にGP-25のsinc $(\pi d u), \operatorname{MTF}_{M}(u), \operatorname{MTFS}_{2}(u)$ を 示す.このとき $\operatorname{sinc}(\pi d u)$ はを $100 \mu \mathrm{m}$ (メーカ公称值) として計算した。したがって，標本開口寸法による影 響は他のシステムより少ない。 そこで, GP-25の保護 膜の厚さがST-VN と同程度であれば，MTFPRE $(u)$ は 
$M T F s(u)$ とほぼ同等の値となるはずである。

瞬時発光を利用したIPの鮮鋭度は保護膜の厚さが影 響するが，保護膜の厚さによるMTFの低下は式(3)を 用いて補正することができる。また，保護膜が薄いと きは補正を必要としない。したがって，保護層が $10 \mu \mathrm{m}$ 程度と薄いときは，IP固有の鮮鋭度㧍よびプリ サンプリングMTFを推定する手段として本手法は有効 である。

\section{3. まとめ}

IPの鮮鋭度を評洒する手段の一つとして瞬時発光を 利用した手法は，従来のアナログの増感紙一フィルム 系と同じであり，その值はCR装置による影響を受け ないが，この手法で求めたMTF值は保護膜の厚さの影
響を受ける。このため，IP固有の鮮鋭度の評価におい て保護層が厚いときはこの厚さを考慮に入れて評価し なければならない。しかし，保護層の厚さが $10 \mu \mathrm{m}$ 程 度のときはIPの固有鮮鋭度を十分に評価できる方法て ある、したがって，瞬時発光を利用したMTFの測定は CR装置導入前の鮮鋭度の検討資料として有效であ る。

\section{謝 辞}

プリサンプリングMTFのデータ（ST-V)を快く提供 してくださった西原貞光氏(広島県立保健福祉大学)に 深謝します。また，英文のご指導をいただきました桂 川茂彦氏(日本文理大学)に深謝いたします。

\section{参考文献}

1) Fujita $H$, Ueda $K$, Morishita J, et al.: Basic imaging properties of a computed radiographic system with photostimulable phosphors. Med Phys, 16 (1), 52-59, (1989).

2) 田中嘉津夫, 他 (内田 勝 監) 著：放射線画像工学. pp. 137-146，才一ム社，東京，(1986）。

3) 藤田広志，上田克彦，大塚昭義，他：輝尽蛍光体を用いた コンピューテッドラジォグラフィの解像特性 I. イメージ ングプレートのMTFの測定. 医用画像情報学会雑誌，4 (3), 89-94, (1987)

4) Giger ML and Doi K: Investigation of basic imaging properties in digital radiography. I.Modulation transfer function. Med Phys, 11 (3), 287-295, (1984).
5）若松秀明，中野 寧，本田 哲：Regius Model-150用輝尽 性蛍光体プレートの開発. Konica Technical Report, 13, 19-22, (1999).

6) Kengyelics SM, Davies AG, and Cowen AR: A comparison of the physical imaging properties of Fuji ST-V, ST-VA and ST-VN computed radiography image plates. Med Phys, 25 (11), 2163-2169, (1998).

7）西原貞光，大村敬子，吉田賢一，他：イメージングプレー 卜 (CR)の基本的な物理特性. 日放技学誌，52(11)，1556$1560, \quad(1996)$

8) 平城 実, 土井邦雄：増感紙・蛍光板の試験法．極光XRAY, 21，13-45，(1967).

Fig. 1 実験配置図.

Fig. 23 種類のイメージングプレートと片面フイルム系の瞬時発光による特性曲線。

Fig. 3 瞬時発光で求めた 3 種類のイメージングプレートMTF $[M T F M(u)]$.

Fig. 4 RP-1Sイメージングプレートの種々なMTF.

(a) $68 \mu \mathrm{m}$ 厚の保護膜があるとき。

(b) 保護膜がないとき.

$\operatorname{MTFM}_{M}(u)$ またはMTFD $(u)$ : イメージングプレートMTF, $\operatorname{MTFS}(u)$ またはMTFSD $(u)$ : 予測したプリサンプリングMTF, $\operatorname{MTF}_{P R E}(u):$ 実測したプリサンプリングMTF, $\operatorname{sinc}(\pi d u)$ : サンプリングアパーチャのMTF.

Fig. $568 \mu \mathrm{m}$ 厚の保護膜があるときとないときの, 瞬時発光で求めたイメージングプレートMTF.

Fig. 6 ST-VNイメージングプレートの種々なMTF.

Fig. 710,20 , および $60 \mu \mathrm{m}$ 厚さの保護膜中における光の拡散によるMTFの劣化.

Fig. $860 \mu \mathrm{m}$ 厚さの保護層における光の拡散による劣化を補正して求めた予測プリサンプリングMTFと実際に測定したRP-1Sイメ ージングプレートのMTF.

Fig. 9 GP-25イメージングプレートの種々なMTF. 